\title{
Middle ear structures in the Permian Glanosuchus sp. (Therocephalia, Therapsida), based on thin sections
}

\author{
Wolfgang Maier ${ }^{1} \&$ Juri van den Heever ${ }^{2}$
}

With 14 figures

\begin{abstract}
Transverse sections of the skull of the Permian therocephalian Glanosuchus sp. were studied with regard to the structures of the middle ear region. It is generally accepted that most of the skeletal elements of the mammalian middle ear are derived from the postdentary bones of the lower jaw. During synapsid evolution there is a gradual transition from a primitive amniote condition to derived mammalian condition; the latter is characterized by the decoupling of the remaining middle ear elements (angular, prearticular, articular) from the dentary, which forms a secondary jaw articulation with the squamosal. Morganucodon from the Triassic-Jurassic boundary represents an evolutionary stage, where both jaw articulations are present in a coaxial position and where the primary joint is a Pready a fully effective sound transmitter. Therocephalians are considered to be a good representation of the transitory state of this evolutionary process; this may be especially true for primitive taxa such as the lycosuchid Glanosuchus, whose anatomy may represent the "groundplan" (ancestral morphotype) of Lower to Middle Permian eutheriodonts. We studied a complete sectional series of a young specimen of Glanosuchus sp. prepared using the grind-and peel-technique. This showed that the reflected lamina of Glanosuchus is in major parts an extremely thin bony plate, which is best interpreted as a sound-receiving element overlying an air-filled recessus of the pharynx. In this specimen, the vestibular foramen and the stapes are preserved in situ; it is likely, however, that both structures were framed by cartilage which fixed the anular ligament. Both the stapes and the quadrate process of the pterygoid are in direct contact with the quadrate. Comparison of the area of the reflected lamina and the vestibular foramen shows that impedance matching was still very ineffective in Therocephalia when compared to extant mammals.
\end{abstract}

Key words: Therapsida, Therocephalia, Glanosuchus, Permian, anatomy, middle ear.

\section{Zusammenfassung}

In dieser Arbeit wurden Transversalschnitte des Schädels von dem Therocephalen Glanosuchus sp. im Hinblick auf die Anatomie der Mittelohrregion untersucht. Allgemein wird angenommen, dass die meisten Skelettelemente des Mittelohres der Säuger aus den postdentalen Knochen des Unterkiefers hervorgegangen sind. Der abgeleitete Zustand des Säuger-Mittelohres entstand demnach durch graduelle Abwandlung der ursprünglichen Amniotenkonstruktion. Der abgeleitete Zustand besteht darin, dass u. a. die drei postdentalen Elemente Angulare, Präartikulare und Artikulare aus dem Verband des Unterkiefers herausgelöst wurden, wobei das Dentale nun das Kiefergelenk mit dem Squamosum bildet. In der permotriassischen Gattung Morganucodon existieren beide Kiefergelenke nebeneinander, obwohl das primäre Kiefergelenk bereits die impedanzwandelnde Funktion übernommen hatte. Die Therocephalen sind ein weiteres Beispiel für eine solche evolutionäre Zwischenstellung, und unter diesen ist die ursprüngliche Gattung Glanosuchus besonders interessant. Sie gilt als beispielhaft für den Zustand unter- bis mittelpermischer Eutheriodonten. In der vorliegenden Arbeit untersuchten wir eine vollständige Schnittserie ('Grind-and-peel-Methode') eines juvenilen Glanosuchus sp. Die Lamina reflexa des untersuchten Stückes bildet eine sehr dünne Knochenlamelle, die sich am ehesten als schallübertragendes Element deuten läßt, das eine luftgefüllte Ausstülpung des Pharynx nach außen hin abschloss. Der Stapes und die Fenestra vestibuli des untersuchten Exemplares sind in situ erhalten, doch ist aufgrund fehlender Knochenränder wahrscheinlich, dass beide Strukturen sich knorpelig fortsetzten und durch ein Anularligament verbunden waren. Sowohl der Stapes als auch der Quadratfortsatz des Pterygoids hatten unmittelbaren Kontakt mit dem Quadratum. Das Flächenverhältnis zwischen der Lamina reflexa und der Fenestra vestibuli bei Glanosuchus läßt auf eine noch nicht sehr effektive Schallübertragung schließen.

Schlüsselwörter: Therapsida, Therocephalia, Glanosuchus, Perm, Anatomie, Mittelohr.

${ }^{1}$ Institute of Systematic Zoology, University of Tuebingen, Auf der Morgenstelle 28, D-72076 Tuebingen, Germany. E-mail: wolfgang.maier@uni-tuebingen.de

${ }^{2}$ Department of Zoology of the University of Stellenbosch, Südafrika. Received May, accepted July 2002 


\section{Introduction}

The evolution of the mammalian middle ear (and the concomitant development of a secondary jaw articulation) is one of the most puzzling structural and functional transformations in vertebrate phylogeny. In the early 19 th century, the problem was recognized and solved, in outline, by comparative embryologists, and its various components were first brought together by Reichert (1837). The story of these discoveries was carefully reviewed by Gaupp (1899) and Russell (1916). Later Gaupp (1913) wrote a magnificent monograph on the "Theory of Reichert", and he added much new ontogenetic evidence from his own research; Gaupp also made great efforts toward integrating the evidence that had been accumulated by palaeontologists, because he clearly realized that only fossils would provide the conclusive test for this theory. At least in German literature, this theory has since been called the "Reichert-GauppTheory".

Palaeontologists have repeatedly discussed the problem of the transition of the primary jaw joint (quadrato-articular articulation) to the secondary squamoso-dental joint. One main task has been the search for the remnants of the postulated extracolumella and the position of the primary tympanic membrane (Westoll 1945, Watson 1953, Parrington 1949, 1955). These studies can not be reviewed here, but see Maier (1990) for a review.

The publication of Allin (1975) marks a breakthrough in the evaluation of the fossil evidence. Gaupp (1913) had already argued that we should not assume the existence of an extracolumella in mammalian forerunners - considering that this element may be a sauropsid specialization. It is clear from looking at the massive columella as well as the massive and fixed quadrate and articular of early pelycosaurs (Romer \& Price 1940) that these bones can not have served for the efficient transmission of airborne sounds. However, sphenacodont pelycosaurs show the first stage of development of the external fossa of the angular (Hopson \& Barghusen 1986). Originally, this fossa was assumed to have contained a portion of the reflected medial pterygoid muscle, but it is now interpreted as housing a pharyngeal recessus, i.e. the forerunner of the tympanic cavity. Allin $(1975,1986)$ demonstrated that this 'angular complex' becomes gradually elaborated in later stages of pelycosaurian and therocephalian evolution:
- The postdentary elements become successively reduced in size and detatched from the dentary;

- the quadrate and adjacent quadratojugal also become smaller and both are only loosely attached to the squamosal;

- the external fossa becomes enlarged and its lateral wall, the reflected lamina, first becomes a thin and expanded bony plate and, finally, the thin rod of the posteroventral frame of the tympanic membrane;

- the retroarticular process of the articulare becomes a free, ventrally projecting lever; probably it only represents the proximal portion of the manubrium mallei, the distal portion, which is inserted in the tympanic membrane, is probably a neomorphic addition.

Advanced cynodonts approach, step by step, the mammalian condition, as documented for example by Morganucodon, where the quadratoarticular ossicles coexists with the new squamoso-dental articulation (Kermack et al. 1973, 1981). Based on marsupial ontogeny, Maier (1987, 1990) has presented a model which explains the translocation of the middle ear complex from the mandibular angle to the basicranium within mammals.

So far, therocephalian morphology has played only a marginal role in reconstructing the evolutionary development of the mammalian middle ear. However, it is evident that the study of therocephalians is important for an adequate reconstruction of the eutheriodont "groundplan". This "groundplan" characterizes an adaptive stage of mammalian evolution that had been reached in middle Permian times, and this ancestral morphotype can provide a starting point for understanding the evolutionary development within the cynodont line.

\section{Material and methods}

The present study was based on one specimen of Glanosuchus sp. (South African Mus., SAM K238a) that was transformed by J.v.d.H. into a sectional series using the grinding and peel-technique. The series is housed in the Department of Zoology of the University of Stellenbosch. Glanosuchus was assigned to the Lycosuchidae, which is probably the sister-group of all other Therocephalia, by van den Heever (1994). That the head was embedded lying on its left side is proven by the observation that both hyoids were shifted to the left side during the taphonomic process (Figs 8-10). The skull is also somewhat compressed bilaterally. Before sectioning, the specimen was documented using Computer Tomography (Fig. 1). The left side of the specimen is well preserved, while its right upper side is weathered. In order to better illustrate the morphology of Glanosuchus, a full grown 

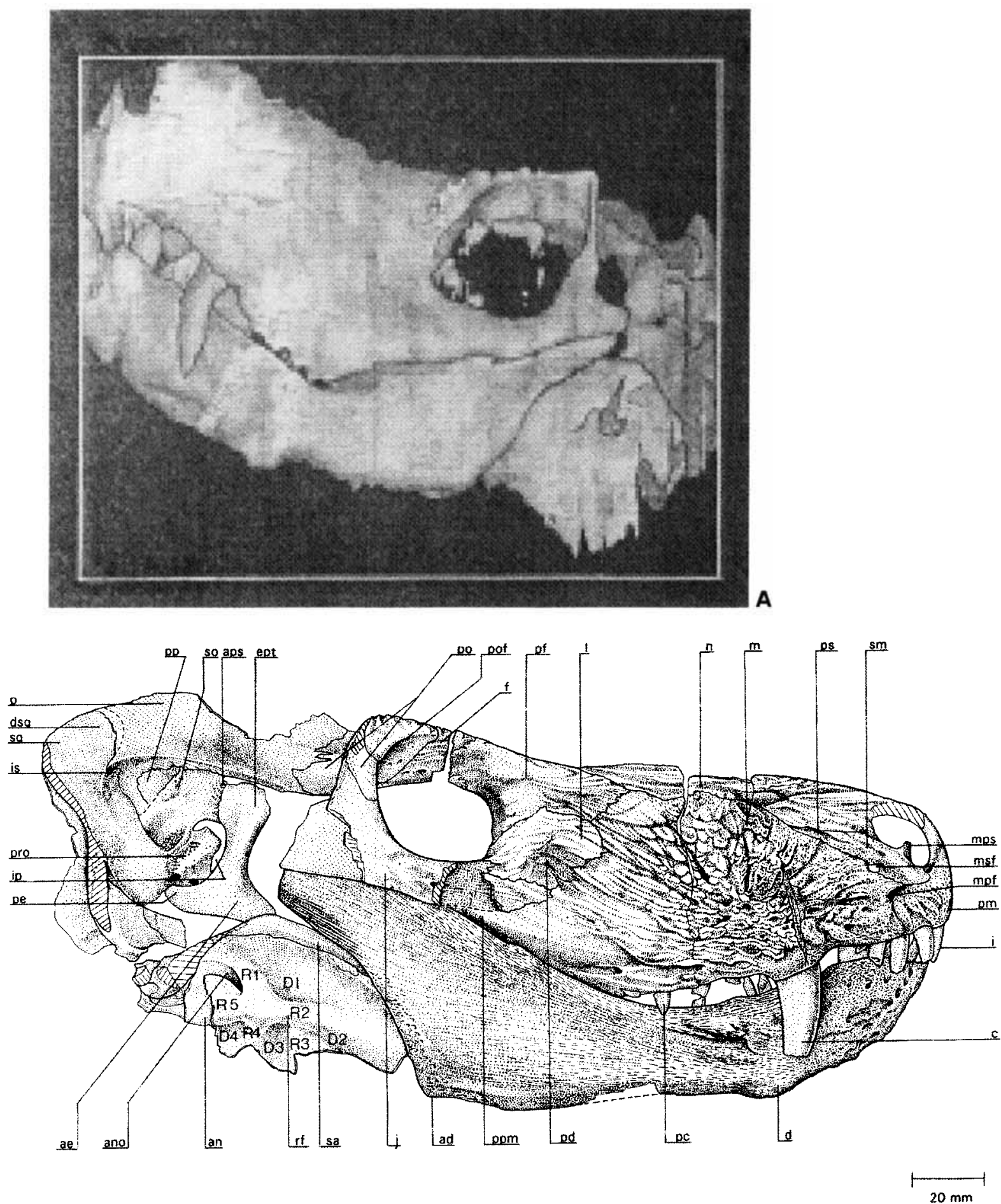

Fig. 1. Side view of a skull of Glanosuchus macrops (from Heever 1994) (A) and the reconstruction of the sectioned specimen of Glanosuchus sp. based on Computer Tomography (B).

specimen of G. macrops is depicted (van den Heever 1994), which shows many anatomical details of this taxon. Glanosuchus was also described and figured by Boonstra (1954: fig. 4)

The specimen of Glanosuchus studied here had a length of $120 \mathrm{~mm}$, and it almost certainly represents a subadult ontogenetic stage; skulls of adults have a length of more than $300 \mathrm{~mm}$. It was ground at intervals of $200 \mu \mathrm{m}$ resulting in 587 peels. W.M. was kindly allowed to study these peel preparations during a visit in 2000 , and drawings were made from selected sections with the aid of a stero-microscope and a camera lucida. The original pen drawings have been redrawn in indian ink and lettered in the Department of Systematic Zoology at the University of Tuebingen.
Anatomical abbreviations: ang: angular; art: articular; bas: basisphenoid; cht: chorda tympani; cor: coronoid; cpd: coronoid process of dentary; den: dentary; ect: ectopterygoid; ept: epipterygoid; fev: vestibular fenestra; fso: suborbital fenestra; hy: hyoid; iv: interpterygoid vacuity; jug: jugal; Ir: lamina reflexa; Mc: Meckel's cartilage (reconstructed); pal: palatine; pra: prearticular; pas: parasphenoid; pbk: parabasisphenoid keel; peo: perioticum; pte: pterygoid; qaj: quadrato-articular joint; qua: quadrate; quj: quadratojugal; rm: recessus mandibularis (reconstructed); sio: interorbital septum (reconstructed); spl: splenial; squ: squamosal; sta: stapes; sua: surangular; ta: auditory tube (reconstructed); tpp: transversal process of pterygoid. 


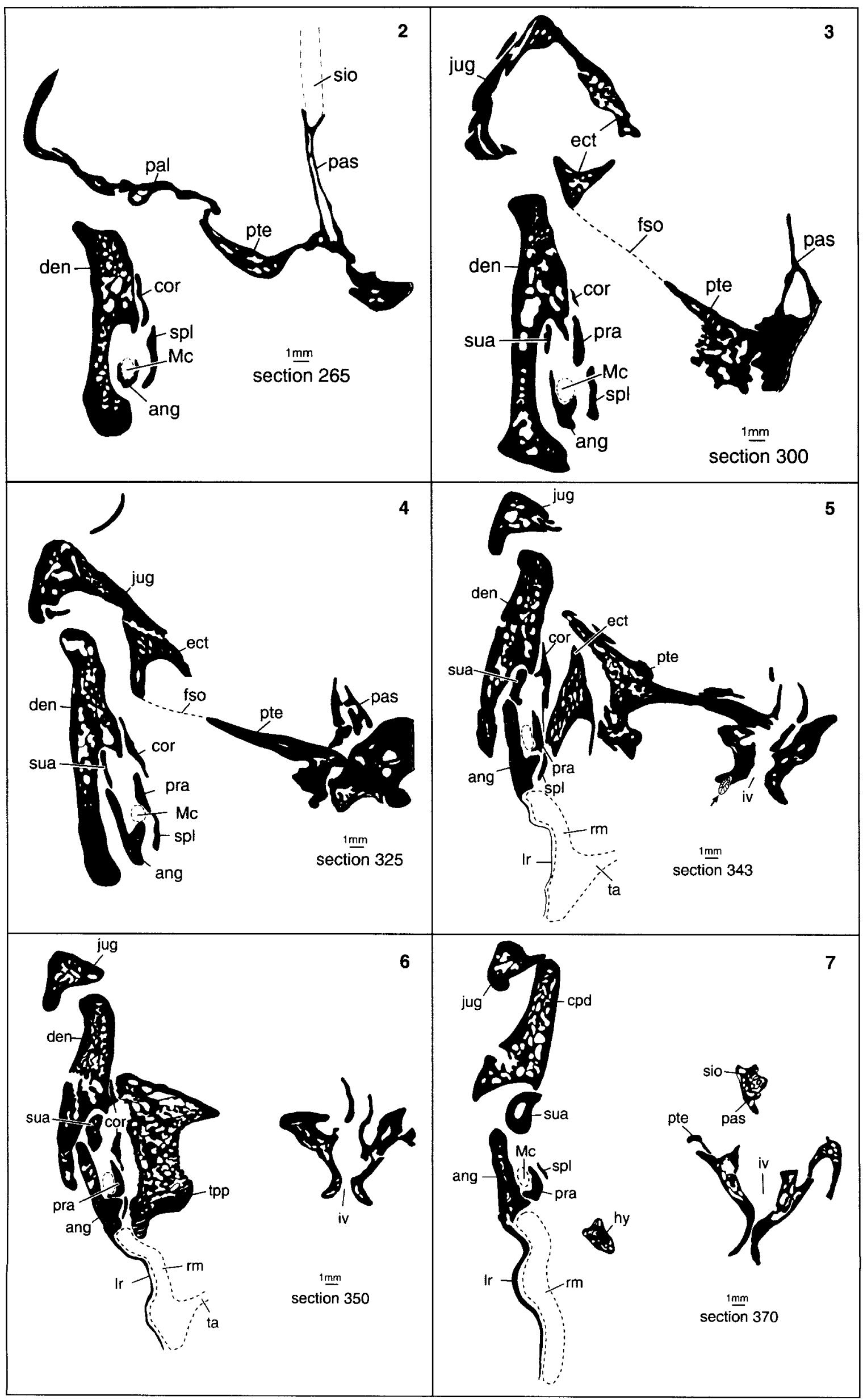




\section{Results}

Transverse sections are presented in a series running in a rostro-caudal direction. The drawings are identified by their section numbers, and thereby the distances between the sections can easily be calculated. Several cross sections from different levels of this same sectional series have already been published (Maier et al. 1996, Maier 1999). Tentative interpretations as to the position of soft tissue structures, such as cartilages and air spaces, are indicated by stippled lines and reconstructions of cartilaginous parts are denoted by small circles.

Section 265 (Fig. 2): This section bisects the mandible at about half length. The palate is closed at this point. There is a vertical bony plate dorsal to the midline, which ends in a rounded groove. We suppose that this bone is a rostral extension of the parasphenoid which supported a thin interorbital septum consisting of cartilage; but it can not be ruled out that this bone is part of the vomer, although it continues posteriorly into the region of the interpterygoid vacuity (see below). The dentary bone shows a spacious medial trough, which is partly covered by a posterior extension of the splenial. The trough houses a gutter-shaped anterior process of the angular, which probably embraced remnants of the Meckel's cartilage.

Section 300 (Fig. 3): At this point, the palate is pierced by a wide suborbital fenestra, which, however, was closed by a strong membrane. Maier et al. (1996) argued that the ventral side of this fenestra may have served as an area of origin for the tensor tympani and tensor veli palatini muscles, whereas parts of the original medial pterygoid muscle may have arisen from its dorsal side. The medial trough, which is now also covered by the rostral process of the prearticular, contains an enlarged angular and the tip of the surangular. The rostral process of the supposed parasphenoidal process is shorter, and broadly fused to the dorsal side of the pterygoid.

Section 325 (Fig. 4): This section bisects the median pterygoid boss and the posterolateral corner of the suborbital fenestra. Only a few denticles are visible on the posterior part of the pterygoid boss (see Fig. 5). The parasphenoid is a broad, isolated element. The dorsal end of the dentary already projects somewhat, as a coronoid process. The medial trough of the dentary is open ventrally and the anterior angular process shows some expansion. It appears that the groove of Meckel's cartilage had begun to separate from the angular groove and to approach the prearticular.

Section 343 (Fig. 5): At this point the coronoid portion of the dentary is shortened ventrally and the angular projects from the medial trough. The reflected lamina (lr) is an extremely thin bony plate $(0.05-0.10 \mathrm{~mm})$, and, presumably, was underlain by an air sac derived from the mandibular recessus of the pharynx (cf. Allin 1975, Allin \& Hopson 1992). The postdentary complex lies in the proximity of the ectopterygoid, and the lateral flange of the pterygoid (section 350, not, Fig. 6). In the midline, a narrow interpterygoid vacuity is seen between the median pterygoid bosses; and on one side, a small pterygoidal tooth can be identified (arrow).

Section 350 (Fig. 6): This section shows the close proximity of the lateral flange of the pterygoid and the postdentary elements of the lower jaw, but, due to bilateral compression, this juxtaposition may be a little narrower than in life. It is likely that this flange functioned as a guide for the lower jaw, provided the gap was filled with loose connective tissue. The irregular lateral surface of the pterygoid flange suggests that there may have been a surface of secondary cartilage - as found on the (non-homologous) mammalian hamulus pterygoideus. This transverse section also shows that the pterygoid flange would not have interfered with what is putatively identified as the mandibular recessus. Both the ventral process of the ectopterygoid and the concave margin of the pterygoid flange may have served as sites of origin for the medial pterygoid muscle and its derivatives (cf. Maier et al. 1996).

Section 370 (Fig. 7): In this section, the coronoid process of the dentary is completely detached from the postdentary elements. The surangular forms a solid bony bar that is well separated from the praearticular-angular-complex. The reflected lamina is considerably thicker in this section, and its lateral prominence appears to be a corrugation of the reflected lamina - probably

Figs 2-7. Thin sections of the skull of Glanosuchus sp. For explanations and abbreviations see text. 
endowing it with greater mechanical stiffness. The cartilage of Meckel is probably located between the crescentic prearticular and the body of the angular. The posterior part of the interpterygoid vacuity seems to be framed by basicranial bones other than the pterygoids, which are in a dorsolateral position. It seems plausible to define these bones as the parabasisphenoid; the interpterygoid vacuity would then be a craniopharyngeal canal leading into the hypophyseal fossa as observed in the embryonic stages of most extant mammals. Dorsal to this canal is a small Yshaped bony rod, which seems to consist of two different components. The broadened rostral end of one hyoid bar is visible near the postdentary complex.

Section 428 (Fig. 8) In this section the lower portion of the reflected lamina is separated from the upper part by a cleft that exposes the external fossa which is here expanded dorsally. The surangular is now a strong vertical plate forming the mechanical axis of the posterior part of the lower jaw. Its lower part is broken into several fragments (see Fig. 9). The prearticular has a lateral rim that most probably housed the Meckel's cartilage, which seems to have had an oval cross section. The prearticular forms a strong medial process that braces the anterior side of the articular (see following section). Just beneath this medial process of the articular transverse sections of the left and right hyoid bones are visible. They must have become shifted to the left underside of the skull during embedding. The basicranium is represented by a narrow parabasisphenoid with a prominent keel. More laterally, the narrow quadrate ramus of the pterygoid contacts the epipterygoid. The basicranial articulation between the basitrabecular process and the epipterygoid of this specimen (sections no. 405 and 413) have been illustrated by Maier (1999). These sections demonstrate that this structure has characteristics of a diarthrosis and excludes the pterygoid, i.e. it is not a basipterygoid joint as seen in sauropsids (Maier pers. obs.).

Section 444 (Fig. 9): This section reveals the ossified posterior end of the cartilage of Meckel, i.e. the articular bone. This bone gives rise to a strong medial process that served as an insertion site for the tensor tympani muscle (cf. Maier et al. 1996). The transition between the Meckel's cartilage and the articular is well represented by cancellous bone in some sections. The medial process is partially braced by the prearticular, which seems to have an opening for the chorda tympani nerve (cht). The dorsal parts of the angular appear to end at this point. The periotic and the basioccipital ossifications consist of cancellous bone that does not always show a well defined surface - suggesting that some cartilage (synchondroses) still existed. Between the neurocranium and the postdentary bones of the mandible there is a vertical bony plate. Its dorsal portion represents the posterior process of the epipterygoid (cf. Heever 1994: fig. 1), whereas the lower part forms the quadrate process of the pterygoid.

Section 465 (Fig. 10): This transverse section bisects both the facial foramen (N VII) and the vestibular fenestra ( $\mathrm{fev}=$ foramen ovale). The footplate of the stapes is clearly separated from the irregular osseous margin of the oval window; we therefore postulate the existence of cartilage on both the stapes and the periotic or basioccipital (stippled areas). Posteriorly, the surangular is fused to the articular for a short distance, but the line of fusion is still discernible (arrows). The medial side of the articular has a concave facet with a somewhat irregular surface; we postulate that it was covered by a layer of articular cartilage. The two hyoids, whose transverse section was compact and narrow in the previous sections, widens posteriorly and they are again changed into cartilage, a situation that suggests that they may have already been fixed to the periotic in a mammalian manner (cf. Maier 1999: fig. 5B). The quadrate ramus of the pterygoid persists as a narrow splint of bone that contacts the quadrate (see Fig. 12), while the prearticular and the angular meet at their posteriormost ends.

Section 483 (Fig. 11): The surangular and articular are again separated, and the articular facet is shifted somewhat more dorsolaterally. This oblique orientation of the articular facets is also evident in prepared specimens (cf. van den Heever 1994: fig. 17). The ventral portion of the articular projects as a free retroarticular process. The neck of the stapes, which seems to run posterolaterally, is fairly slender and exhibits a triradiate transverse section.

Section 490 (Fig. 12): This section shows both the articular and the quadrate. Both bones are well separated, but their opposing surfaces have concave facets; we conclude therefore that fairly thick pads of articular cartilage formed the quadrato-articular joint (qaj = primary jaw articulation). The retroarticular process of the articular projects medially. The stapes abuts the medial 


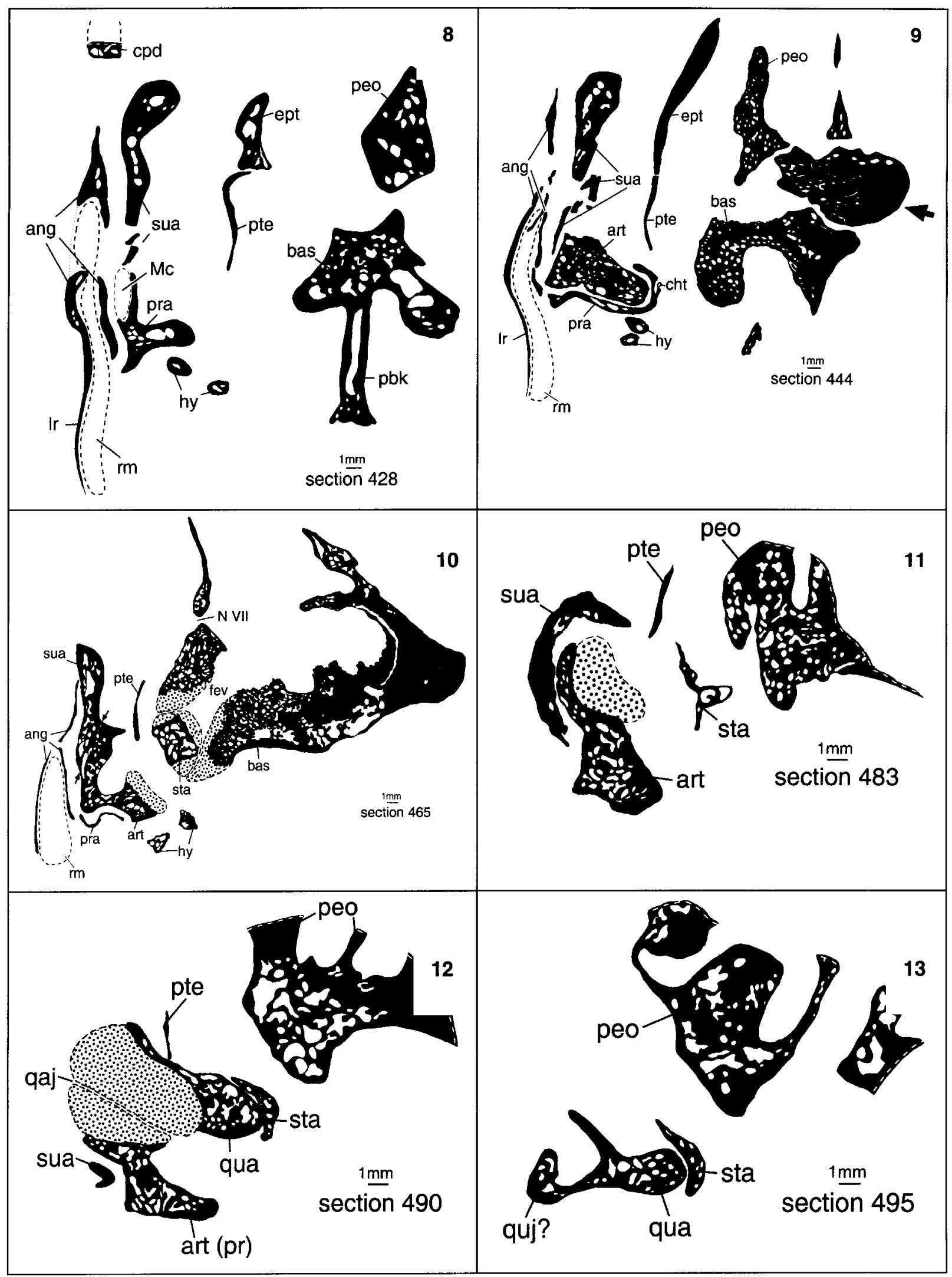

Figs 8-13. Thin sections of the skull of Glanosuchus sp. For explanations and abbreviations see text.

projection of the quadrate, much as it does in the incudo-stapedial joint of mammals. The posterior end of the pterygoid contacts the dorsal side of the quadrate.
Section 495 (Fig. 13) Posterior to the jaw articulation, the quadrate is evident as a small bone with a dorsal peg. On its medial side it is still in contact with the stapes. Laterally, there is a bony 
prominence that may represent a small quadratojugal, but no suture could be discovered.

\section{Discussion}

Although transverse sections of suitable fossils have long been considered as a valuable source of details concerning synapsid anatomy (e.g., Broom 1936, Olson 1944, Cluver 1971) there are few comprehensive descriptions of the ear region. The peel-technique developed by Sollas \& Sollas (1914) at least avoids complete loss of the fossil, and even allows microscopic study of the texture. Modern radiographic techniques are increasingly being used in palaeontology (cf. Rowe 1996), but Computer Tomography (CT) will be unable to provide the same histological resolution as serial grinding, although it is much more economic and it allows rapid 3D-imaging. Although we realize that it would have been advantageous to present 3D-reconstructions of the data collected, this was not possible. While many of our findings confirm what has already been published on therocephalian cranial anatomy, many details are at least seen from a different perspective, while others seem to be useful in obtaining a better understanding of the theriodont 'groundplan'.

The anteriormost ends of the functioning postdentary elements, as represented by the angular, surangular and cartilage of Meckel are only loosely inserted into the medial trough of the dentary; it remains questionable as to which type of tissue surrounded these elements and how they were eventually fixed to the dentary. Rostrally, the trough is covered medially by the splenial. More posteriorly, the coronoid and the anterior process of the prearticular also form the medial cover of the trough, but the prearticular soon gains closer contact with the cartilage of Meckel.

After becoming independent from the ventral margin of the dentary, the angular forms the extremely thin bony plate of the reflected lamina. Although we were lacking a calibrated ocular lens, we are certain that its thickness was less than $0.1 \mathrm{~mm}$ anteriorly, whereas it tends to become somewhat thicker posteriorly. The lamina reflexa reaches a maximum ventral projection of about $10 \mathrm{~mm}$. Whereas rostrally the lamina reflexa is a complete plate, its posterior end takes

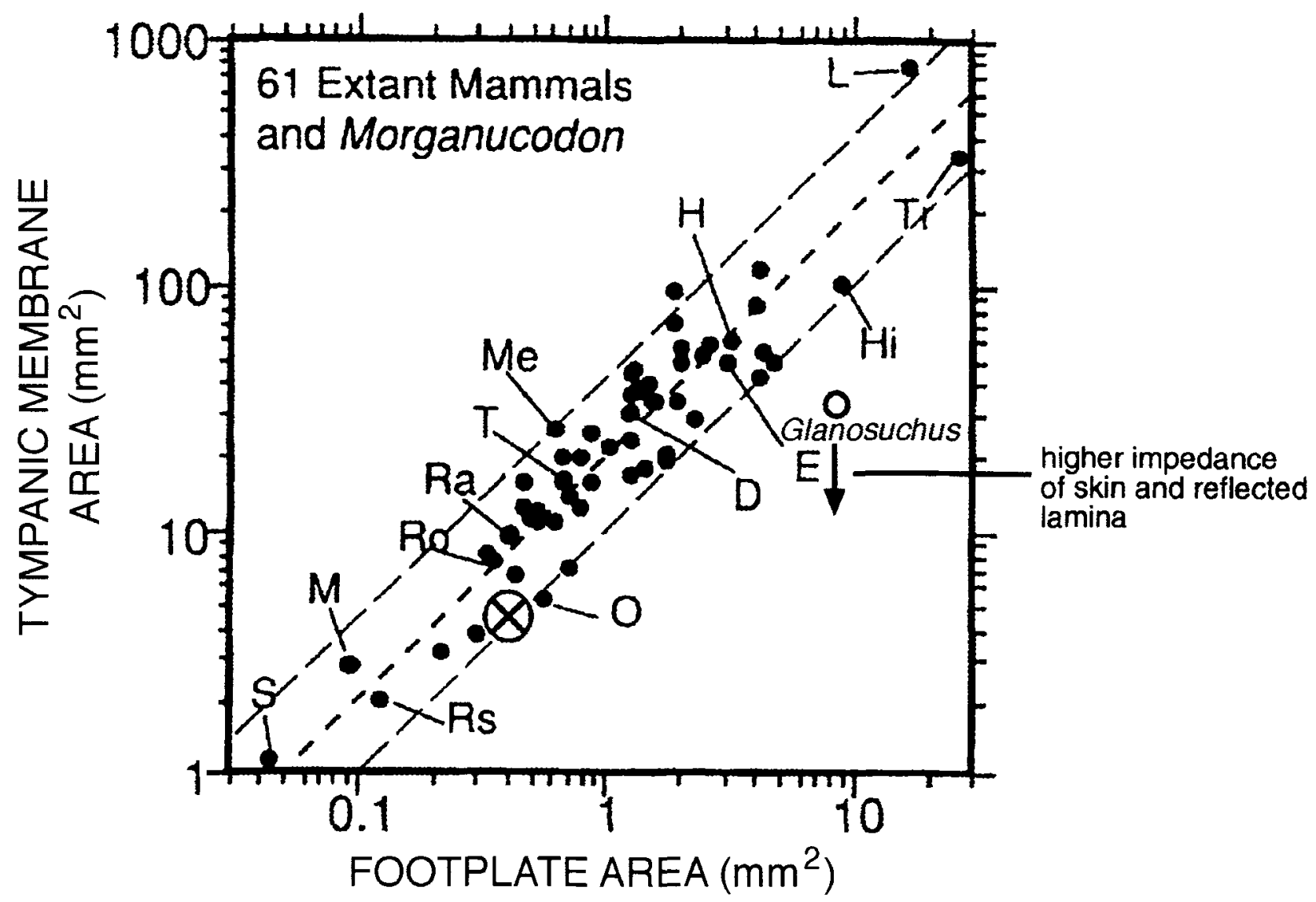

Fig. 14. Relation of tympanic membrane versus footplate area in the studied specimen of Glanosuchus sp., compared to Morganucodon and extant mammals. For abbreviations see Rosowski (1992). 
the forms of a free ventrolateral process. The radially running spokes that are often seen on the lateral aspect of the lamina reflexa, are not thickenings but corrugations of the bony plate, perhaps enabling the thin plate to become stiffer while keeping its mass low. It seems most reasonable to us that the lamina reflexa was underlain by an airfilled recessus of the pharynx, which should have functioned as a resonating chamber.

It is interesting to note that the quadrate process of the pterygoid can be followed to its loose attachment with the quadrate. Rostrally it is apposed to the lower edge of the epipterygoid. This condition is reminiscent of the plesiomorphic condition of the quadrate-palatal bar, but due to the reduction of the quadrate, and of increasing akinetism, the posterior pterygoid certainly had no further relevant mechanical functions. It may be speculated whether this contact was involved somehow in transmitting vibrations from the snout to the quadrate.

The footplate of the stapes does not fit perfectly into the vestibular fenestra; we suggest therefore that both the rim of the fenestra and the footplate were cartilaginous as it is seen in fetal mammals. Posterolaterally, the stapes has a broad contact with the medial side of the quadrate. Both the quadrate and the articular have opposing facets suggesting that they were covered by pads of articular cartilage that formed the primary jaw articulation.

We have calculated, from our reconstruction, that the area of the stapes foot plate was about $8 \mathrm{~mm}^{2}$, and that of the tympanic skin overlying the tympanic recess as about $30 \mathrm{~mm}^{2}$. This gives a fairly low pressure ratio of only about 4.0. Inserting our data into the diagram presented by Rosowski (1992) shows that this ratio is distinctly below that for mammals (Fig. 14). Further, because no true tympanic membrane existed, the high impedance of the skin and of the bony reflected lamina has to be taken into account, which certainly further lowered hearing sensitivity. Although evolutionary development of the middle ear was well on its way to the mammal condition in primitive therocephalians - and in primitive therapsids as well - its effectivity was certainly not far advanced. However, evolutionary optimization is not measured in absolute terms, but by its relation to contemporaneous and sympatric competitors, i.e. it must have been good enough for the Permian world.

\section{References}

Allin, E. A. 1975. Evolution of the mammalian ear. - Journal of Morphology 147: 403-438.

- 1986. The auditory apparatus of advanced mammal-like reptiles and early mammals. In Hotton, N., McLean, P. D., Roth, J. J. \& Roth, E. C. (eds). The Ecology and Biology of Mammal-like Reptiles: 283-294. Smithsonian Institution Press, Washington

Allin, E. A. \& Hopson, J. A. 1992. Evolution of the auditory system in Synapsida ('Mammal-like reptiles' and primitive mammals) as seen in the fossil record. In Webster, D. B., Fay, R. R., Popper, A. N. (eds). The Evolutionary Biology of Hearing: 587-614. Springer, New York.

Boonstra, L. D. 1954. The pristerognathid therocephalians from the Tapinocephalus - zone in the South African Museum. - Annals of the South African Museum 42: 65-183.

Broom, R. 1936. On the structure of the skull in the mammal-like reptiles of the suborder Therocephalia. - Philosophical Transactions of the Royal Society of London B 226: $1-42$.

Cluver, M. A. 1971. The cranial morphology of the dicynodont genus Lystrosaurus. - Annals of the South African Museum 56: 155-274.

Gaupp, E. 1899. Ontogenese und Phylogenese des schalleitenden Apparates bei den Wirbeltieren. -- Ergebnisse der Anatatomie und Entwicklungsgeschichte 8 (1898): 990-1149.

- 1913. Die Reichertsche Theorie. - Archiv für Anatomie und Entwicklungsgeschichte 1912 (Supplement): 1-416.

Heever, J. van den 1994. The cranial anatomy of the early Therocephalia (Amniota: Therapsida). - Annals of the University of Stellenbosch 1994 (1): 1-59.

Hopson, J. A. \& Barghusen, H. R. 1986. An analysis of therapsid relationships. In Hotton, N., McLean, P. D., Roth, J. J. \& Roth, E. C. (eds). The Ecology and Biology of Mammal-like Reptiles: 83-106. Smithsonian Institution Press, Washington.

Kermack, K. A., Musset, F. \& Rigney, H. W. 1973. The lower jaw of Morganucodon. - Zoological Journal of the Linnean Society 53: 87-175.

- 1981. The skull of Morganucodon. - Zoological Journal of the Linnean Society 71: $1-158$.

Maier, W. 1987. Der Processus angularis bei Monodelphis domestica (Didelphidae, Marsupialia) und seine Beziehungen zum Mittelohr: Eine ontogenetische und evolutionsmorphologische Untersuchung. - Gegenbaurs Morphologisches Jahrbuch 133: 123-161.

- 1990. Phylogeny and ontogeny of mammalian middle ear structures. - Netherlands Journal of Zoology 40: 55-74.

- 1999. On the evolutionary biology of early mammals with methodological remarks on the interaction between ontogenetic adaptation and phylogenetic transformation. - Zoologischer Anzeiger 238: 55-74.

Maier, W., Heever, J. van den \& Durand, F. 1996. New therapsid specimens and the origin of the secondary hard and soft palate. - Journal of Zoological Systematics and Evolutionary Research 34: 9-19.

Olson, E. C. 1944. Origin of mammals based upon the cranial morphology of therapsid suborders. - Special Papers of the Geological Society of America 55: 1-155.

Parrington, F. R. 1949. Remarks on a theory of the evolution of the tetrapod middle ear. - Journal of Laryngology and Otology 63: 580-595.

- 1955. On the cranial anatomy of some gorgonopsids and the synapsid middle ear. - Proceedings of the Zoological Society of London 125: 1-40.

- 1979. The evolution of the mammalian middle and outer ears: a personal review. - Biological Reviews 54: $369-387$. 
Reichert, C. 1837. Über die Visceralbogen der Wirbeltiere im Allgemeinen und deren Metamorphosen bei den Vögeln und Säugetieren. - Archiv für Anatomie, Physiologie und wissenschaftliche Medizin 1837: 120-222.

Romer, A. W. \& Price, L. I. 1940. Review of the Pelycosauria. - Special Papers of the Geological Society of America 28: $1-538$.

Rosowski, J. J. 1992. Hearing in transitional mammals: predictions from the middle-ear anatomy and hearing capabilities of extant mammals. In Webster, D. B., Fay, R. R. \& Popper, A. N. (eds). The Evolutionary Biology of Hearing: 615-631. Springer, New York.
Rowe, T. 1996. Brain heterochrony and origin of the mammalian middle ear. In Ghiselin, M. T. \& Pinna, G. (eds): Perspectives on the History of Life: 71-95. Memoirs of the California Academy of Sciences, No. 20 San Francisco.

Russell, E. S. 1916. Form and function. A contribution to the history of animal morphology. - 383 pp., John Murray, London.

Sollas, I. B. J. \& Sollas, W. J. 1914. A study of the skull of Dicynodon by means of serial sections. - Transactions of the Toyal Society London, Ser. B, 204: 201-226.

Watson, D. M. S. 1953. Evolution of the mammalian middle ear. -- Evolution 7: 159-177.

Westoll, T. S. 1945. The mammalian middle ear. - Nature 155: $114-115$. 